\title{
Analysis of Quality Control and Safety Management in Electrical Engineering
}

\author{
Zhang Pingli Puyang Division of Municipal Facility Management, Puyang, Henan, 457000 \\ Fang Yonghao Puyang First Senior High School, Puyang, Henan, 457000 \\ Fang Fei MYJ Chemical Co., Ltd., Puyang, Henan, 457000
}

\begin{abstract}
In the development process of the society nowadays, electrical engineering has been widely used with remarkable results, but there are still some problems in the course of actual management, which requires effective technical measures to control the quality in electrical engineering and the enhancement of safety management work. Therefore, in order to better ensure safety management requirements in electrical engineering and strengthen related trainings and thus better carried out safety management and quality control to meet respective requirements in the real world, in this paper, a brief analysis is conducted in quality control and safety management in electrical engineering.
\end{abstract}

Key words: Electrical engineering; quality control; safety management

\section{Published Online: 31st Jan 2018}

\section{Construction characteristics of electrical engineering for building}

\subsection{Construction is large in size with a long duration}

In general, like those in other building engineering, protects in electrical engineering for building are mostly large, only one of them requires a lot of manpower and materials with a long duration. In the event that the project is huge in size with long duration and very outstanding importance, construction personnel will inevitably face high working pressure when they carry out construction. In addition, there are a wide variety of construction projects and complicated construction processes. When the work is performed, it is required not only to take care of the whole construction process but also to give consideration to each procedure and each step in the works; hence there might be problems such as deficiency in safety management of projects.

\subsection{Contents of the construction is complex and dangerous}

Subjects in the construction carried out by construction personnel is not fixed and will experience certain transitions with projects progressing, such as, the installation work of distribution box, wire laying and lightning protection grounding construction, these projects are comparatively complicated and highly dangerous when operated, once conductors are disorderly connected or unreasonably laid, either workload is increase and work time is extended, or the life safety of construction personnel is involved. Managers cannot exert strict control over each construction subject, and once safety problems happen, handling them will be much troublesome.

\subsection{Construction environment is relatively poor}

On-site environments of construction of electrical engineering for building are mostly poor, and many of such constructions are field and outdoor operations. Sometimes construction personnel have no choice but to live in temporary buildings without appropriate safety measures, possibly encounter natural factors detrimental to construction of works at any time and lack favorable means in aspects of managements of things like equipment and materials, therefore, there is a big difficulty in the safety management of construction of electrical engineering for building.

\section{Disadvantages discovered in the construction of electrical engineering}

2.1 Deviation appears in materials used in equipment 
With the rapid development of economy in our country, more and more devices and materials are seen in the market. All these devices and new materials largely improve quality and efficiency but their costs are universally high, so some enterprises will choose some common materials in the process of application, planting the seeds of large hidden quality risks. Sometimes unexpected things occur in the works, such as occurrence of power line corrosion, which will cause electricity leakage or electricity failure, affecting not only effective implementation of construction, but safety of construction personnel, therefore control over this regard is very important.

\subsection{Deviation occurs when different types of cables are handled}

Corresponding treatment will be conducted on cables when construction is carried out, including run-through and wrapping. Some construction crews have no understanding of the importance of wire treatment and do not operate strictly in accordance with related requirements during construction so that cables do not meet related standard requirements, causing great inconveniences to the implementation of subsequent work.

\subsection{Personnel problems}

Safety management staffs of electromechanical equipment for electrical engineering generally do not accept formal technical training before they begin employment, but today knowledge is increasingly frequently updated, so enterprises should formulate appropriate control strategies and call on employees to continuously receive new education at work, learn new theories, knowledge, technologies and methods, constantly improve the learning of employees from expertise, and further move the development of construction technologies for electrical engineering into a better direction. Moreover, there are certain risks in the operation of control management of construction quality for electrical engineering that might impact the life of people, for example, short circuit or broken circuit probably occurs in the important operating machinery, computer connection systems do not dock reaction system, and the operation of control management of construction quality in electrical engineering faces great challenges. Technical supervision and overall quality for the operation of control management of construction quality in electrical engineering must be better regulated to constantly eliminate existing hidden risks.

\section{Quality control measures for electrical engineering}

\subsection{Better accomplishing preparation work for construction}

Before the construction of electrical engineering for building formally commence, related staffs should carefully review lists and check if relevant requirements are rigidly followed, study construction drawings seriously and formulate construction schemes in detail. Moreover, they should gain approvals from related construction organizations and better accomplish preparation work earnestly before construction. Firstly, related staffs should carefully and comprehensively study and analyze design drawings, communicate and exchange with designers timely, get a full understanding of the goals and intentions of designers to design drawings, make records of disclosure, and mark the cross sections of operation detailedly and expressly; secondarily, brackets and roués of engineering pipes are better arranged according to specific construction schemes, especially for devices in the bottom. Furthermore, it is required to better carry out construction arrangement and planning and accomplish pre-burying work before construction, and thus effectively reduce damages to components. Besides, it is required that corresponding deployment work be well done based on construction technologies and construction materials used.

\subsection{Enhancing quality control at the equipment and material stage in the course of construction}

Equipment and materials are an integral part of electrical engineering and have a great influence on overall quality; hence it is necessary to strictly control materials and equipment when construction takes place so as to better ensure construction efficiency and engineering quality. Equipment and materials used in electrical engineering are required to be rigorously controlled by the supervisor before construction to make sure these material and devices can comply with respective quality requirements and meet requirements of design conditions and enter the construction site only when signatures and approval are obtained. In addition, it should be noted that the quality of equipment and materials requires the principle of the one who buy it takes the responsibility for it and the one should bear the responsibility in the acceptance process. In case problems are found, proceedings should be strictly followed.

\subsection{Quality control in electrical installation}


Nowadays, electrical installation mainly includes the following contents: installations of sockets, lights and distribution boxes etc. Focused control is required and the following tasks should be well done when construction operation is performed: First, operation is performed and devices are reasonably installed according to construction drawings. For example, the control scope of the ceiling fan in relation to the position of the hook box is within $50 \mathrm{~mm}$, and the switch box should be installed in a distance of $180 \mathrm{~mm}$ from the doorframe. The distances of various lights from the center of the ceiling fan should be reasonably controlled, normally less than $5 \mathrm{~mm}$ etc. Second, when the lighting distribution box is installed, pipelines require a silo and are repeatedly laid in an exposed manner, the spacing between pipelines should be set and various pipelines and distribution boxes be reasonably arranged. For the installation of the remaining telephone distribution boxes and distribution boxes, a recessed wall mounting method is used to better ensure overall aesthetics. Three-hole sockets and bedside lamps now are mainly installed in a concealed way. In addition, PE wires are mostly used in electrical installation.

\subsection{Quality control in concealed works}

Quality control in concealed works is also very important and has a huge impact on overall quality; therefore the following tasks should be well done: First, supervision should be enhanced to ensure overall safety. Appropriate staffs are arranged to check the effect of construction, the likes of grounding grids and wedding in the basement should be secured and existing welding points be reasonably arranged. The registration of related work needs to process effectively. Moreover, it is required to coordinate civil engineering work, check the conduits in the precast concrete, and make a respective record of checking results and submit it to the supervisor, and hierarchical quality control is conducted after the signature by the supervisor. Second, the welding of the grounding grid is examined. It is required to keep the the management department and the owner informed in advance before the grounding connectivity test and excavation and to better reduce safety accidents. Subsequent checking work is done after the examination by both parties to ensure engineering quality.

\subsection{Strengthening personnel management}

In the case of modern management, personnel management is crucial. The execution body of electrical engineering itself is each person participating in construction. We should attach importance to personnel management and proactively improve the implementation effect of personnel management work. Construction enterprises should implement various rules and regulations as well as technical standards and specifications effectively, adhere to the electrical construction principle of "Quality First, Prevention Oriented" strictly, make final checks and carry out quality control in the construction rigorously, value the construction activities in electrical engineering ideologically and consciously, and better perform technical disclosure and control ahead of time with respect to the important sections where quality problems might occur. For key positions, it has to be ensured that special operation personnel begin employment with certification, and personnel evaluation and training work should be well done regularly. In the implementation of personnel management work, training and education should be carried out from the perspective of technologies and professional ethics. In the training, it is required to make in-service employees aware of quality inspection, technical installation specifications etc. correctly from a technical angle and allow construction personnel to have a strong sense of responsibility from the perspective of professional ethics. For problems in personal management, it is also required that effective improvement of related systems be realized timely and the behaviors of in-service employees are normalized using systems from the perspective of the improvement of the system of punishment and awards.

\subsection{Concurrent control in the construction of electric installation works}

Concurrent control means quality control and management are performed on the construction of electrical installation works during the construction so as to reach the goals of improving quality in construction works. Concurrent control is a core step in the control process of construction quality and a key part that impacts the quality in construction works. Accomplishing concurrent control has a decisive significance in the effective improvement of construction quality of electrical installation works. Generally, concurrent control includes two parts: self-control of construction organizations and quality supervision of supervision institutions and self-control of construction organizations is more important. In practice, two aspects should be organically combined to jointly realize quality management of construction of 
electrical installation works in the accomplishment of concurrent control in the construction of electrical installation works. In general, concurrent control in electrical installation works should include the following aspects: First, full ex-ante analysis is carried out on each procedure in the process of electrical installation to ensure successful advancement and implementation of procedures, and it is also required to proceed in strict accordance with related standards in the docking process of procedures, for example, high-voltage electrical equipment on the pole is energized only if it is tested and qualified after installation; lamps to be installed at height are installed only if they are qualified in on-the-ground power on-off testing. For the installation of closed and plug-in bus bars, the setting position of brackets cam be determined only if the construction of main structures and indoor ground floors is completed and ground floor level and site clearing are reviewed. All these should strictly follow corresponding provisions to finish the docking of procedures. On the other hand, examination should be conducted by professional personnel after the completion of each procedure to rigorously make sure each procedure reach respective quality standards and practicably ensure that the next procedure proceeds only if the previous procedure is qualified in quality. A final check should be performed strictly on quality to ensure quality safety in the construction of electrical installation works.

\subsection{Ex-post governance in the construction of electrical installation works}

Ex-post governance is also an important step in the enhancement of construction quality in electrical installation works. It is mainly conducted at the later stage of the construction and in the completion stage of electrical installation works, mainly aiming to examine if respective equipment runs well and reaches corresponding national quality standards and owner requirements, and to evaluate overall construction effects of construction organizations. Its main working contents are: completion materials of construction organizations are reviewed; respective quality inspection reports and various technical documents provided by construction organizations are audited; all the documents and materials related to construction quality of electrical installation works, such as drawings, material quality conformity certifications, inspection reports, concealed construction records, are sorted out, and eventually catalogued and filed; overall quality status and levels of electrical installation works are evaluated together with related organizations, and construction organizations are notified of performing reworking tasks if related quality problems are found, and completion acceptance is finally finished.

\section{Implementing safety management in electrical engineering}

\subsection{Ensuring safe voltage grade and safeguarding working environment}

Safe voltage refers to a voltage that will surely not cause personal injury when a construction person directly touches it by its body without wearing any protective equipment. Currently, the safe voltages in our country are divided into five categories. Lots of data show a safe voltage, as long as it is over $24 \mathrm{~V}$, might impact and endanger the human body to some extent. Therefore, to take the safety of construction personnel into account, electrical engineering enterprises should formulate corresponding construction and operation specifications, electric operation workers should wear professional protective tools in construction and a safe and reliable construction environment is offered for them.

\subsection{Accomplishing the installation and protection work for electric equipment}

AT the electrical construction stage, employees should accomplish the installation work of electrical equipment and the protection work for facilities should also be accurate and efficient. To ensure accuracy and regularity in the working process, a final check shall be made strictly on equipment sizes and quality of components like switches. Installation locations of electrical equipment and its precautions on distribution are also remarkably important. In the installation of lines, the thickness of wall tubes shall not be too small; the burying depth of pipes should be appropriate and the burrs on the metal pipe will be flattened. In the installation and protection, attention should be paid to details to eliminate unnecessary hidden safety risks. After the completion of installation, it is also required to invite experts to carefully check the completion quality, electricity distribution matters should be approved one by one, meanwhile, it is required that checking results are recorded timely for later perusal in subsequent maintenance.

\subsection{Improving safety awareness of electrical engineering staff}

In the construction of electrical works, it is required to put rules and regulations in place and accomplish 
propaganda work of safety knowledge to improve safety awareness of staff. Especially, construction personnel on the construction site should complete the work of training in safety knowledge, on-site instructions shall be offered to construction personnel to achieve combination of training and supervision and improve safety awareness of construction personnel. So in the construction of electrical works, it is necessary to constantly improve construction management systems according the construction reality of electrical works and make construction management scientific and reasonable to reduce the occurrence of accidents from the origin.

\subsection{Implementing prevention and management control mechanisms}

Prevention and management control mechanisms shall be implemented in the electrical engineering management, a full play is required to be given to its role of supervision, supervision management personnel are called on to strictly execute related operation specifications, procedural supervision management is carried out in the construction of electrical works to ensure improvement of construction efficiency of electrical works. For construction projects of electrical works, responsibilities should be implemented and the consistence of powers and responsibilities shall be achieved. If problems exist in the construction of works, the implementation of rectification is needed to ensure stable operation of equipment.

\subsection{Implementing intelligentized safety management in electrical works}

Utilization of intelligent zed technologies in the construction of electrical works means carrying out real-time monitoring in electrical works to enable works operation to meet management requirements. Hidden safety risks exist when the construction of electrical works is in the operational state, and real-time monitoring systems can timely discover safety problems in the construction of works through monitoring, and take effective measures to solve these problems on time and help improve construction efficiencies of electrical works. Intelligentized technologies can remotely control various devices used in the construction of electrical works and allow supervision personnel to implement remote regulations without needing to work on site, and automatically schedule and control the devices on the construction site by adjusting parameters.

In a word, with the rapid development of economy, the construction of control management of construction quality in electrical works gets closer to our daily production and life. It is an extremely complicate comprehensive process. Safety and timeliness in the supervision management of safety quality are more difficult in the construction of electrical works than in other industrial sectors. Therefore, a strong technical means is required to effectively manage electrical engineering projects and guarantee engineering quality while ensure the life safety of construction personnel.

\section{References}

[1]Dai Jin. Quality control and management in electrical construction [J]. Telecom World, 2016 (19): 189-190.

[2]Xu Taihong. A study on quality control and safety management in the construction of building electrical works[J]. Green Environment

Protection Building Materials. 2016 (09): 137.

[3]Geng Liyang. Safety management and quality control in electrical engineering $[\mathrm{J}]$. Heilongjiang Science, 2016, 7 (18): 58- 59.

[4]Song Minghui. A study on quality control and safety management in electrical engineering [J]. Housing and Real Estate, 2016 (24): 182- 183. [5]Wang Jiangbo, Song Xiaojun, Li Yueqiao. Analysis on quality control and safety management in electrical engineering $[\mathrm{J}]$. Shandong Industrial Technology, 2016(13):167. 